\title{
Non-communicating hydrocephalus decades after spinal dermoid resection
}

\author{
Hetal Patel, Michael A Casey, Ajeet Gordhan
}

\begin{abstract}
Introduction: We present a case of acute noncommunicating hydrocephalus due to fat droplet obstruction of the cerebral aqueduct, fifty-one years after resection of a spinal dermoid tumor. Case Report: A 71-year-old male presented with sudden onset of neck pain and gait instability. He had prior complete surgical resection of a cervical dermoid cyst in 1959. Follow up magnetic resonance imaging (MRI) in 2007 showed intracranial fat signal droplets within the posterior fossa. An MRI examination obtained in 2012 demonstrated hydrocephalus consequent to fat droplet obstruction at the aqueduct of sylvius which was not present in MRI study done in 2007. Conclusion: To our knowledge there are no published reports of delayed post spinal dermoid resection subarachnoid fat droplet migration leading to acute non-communicating hydrocephalus.
\end{abstract}

Keywords: Dermoid cyst, Hydrocephalus, Intraspinal dermoid, Cerebral aqueduct

Hetal Patel ${ }^{1}$, Michael A Casey ${ }^{2}$, Ajeet Gordhan ${ }^{3}$

Affiliations: ${ }^{1} \mathrm{MD}$, Medical student, Saint Louis University School of Medicine, 1402 S. Grand Blvd, St. Louis MO, 63104, USA; 'DO Neurosurgery resident, Department of Neurosurgery, Advocate Bromenn Hospital, 1304 Franklin Avenue, Normal, IL, 61761, USA; ${ }^{3}$ MD Department Chair, St Joseph Medical Center, Department of Neurointerventional Radiology, 2200 East Washington Street, Bloomington, IL, 61701, USA.

Corresponding Author: Ajeet Gordhan, MD, St Joseph Medical Center, Department of Neurointerventional Radiology, 2200 East Washington Street, Bloomington, IL, 61701, USA; Tel: 1309826 6009; Fax: 1309663 3135; Email: agordhan@hotmail.com

Received: 27 July 2012

Accepted: 17 October 2012

Published: 01 March 2013
Patel H, Casey MA, Gordhan A. Non-communicating hydrocephalus decades after spinal dermoid resection. International Journal of Case Reports and Images 2013;4(3):165-168.

$* * * * * * * * *$

doi:10.5348/ijcri-2013-03-286-CR-7

\section{INTRODUCTION}

Intracranial dermoid cyst rupture leading to noncommunicating hydrocephalus is well documented in literature [1]. However, there are only two case reports of ruptured spinal dermoid cysts leading to hydrocephalus. In each of these cases fat droplet obstruction within the subarachnoid space occurred prior to resection of the cysts [2]. Cephalad migration of subarachnoid fat droplets from the spine and subsequent intracranial complications has been previously described [3]. Delayed subarachnoid fat droplet migration after spinal dermoid resection leading to acute non-communicating hydrocephalus has not been previously reported in literature.

\section{CASE REPORT}

A 71-year-old male presented with sudden onset of neck pain and gait instability. In 1959, he had multilevel laminectomies for gross total resection of a cervical extramedullary, intradural dermoid cyst. No intracranial involvement of the dermoid was noted at the time. The medical and surgical history was otherwise non-contributory.

On physical examination, he was normotensive, alert and orientated with fluent speech. He demonstrated gait ataxia without nystagmus, dysmetria or dysdiadochokinesis. 
Cranial nerves were intact with no motor or sensory deficit.

Review of routine follow up magnetic resonance imaging (MRI) scan done in 2007 revealed recurrence of dermoid fat droplets within the cervical spine with cephalad migration into the subrarachnoid spaces of the posterior fossa, without hydrocephalus (Figure 1A).

Brain MRI examination obtained during the current admission, revealed obstructive non communicating hydrocephalus consequent to a fat droplet within the cerebral aqueduct that was not present on the MRI study obtained in 2007 (Figure 1 B). Enlargement of the lateral and third ventricles with transependymal cerebrospinal fluid (CSF) flow was identified (Figure 2 $\mathrm{A}-\mathrm{C})$. The hydrocephalus and the patient's symptoms resolved after a ventriculoperitoneal shunt was placed.

\section{DISCUSSION}

Dermoid tumors in the central nervous system (CNS) are very rare. Intracranial dermoid cysts account for less than $1 \%$ of all intracranial tumors and intraspinal dermoid tumors comprise about $1.1 \%$ of all intraspinal tumors $[3,4]$. Dermoid cysts form in the third through fifth embryologic weeks when the neural groove is closing to form the neural tube [3]. They result from inclusion of aberrant ectodermal tissue in the spinal canal [4].

Dermoid cysts are comprised of a fibrous external capsule with a layer of stratified squamous epithelium and contain dermal tissue such as sebaceous glands, hair, sweat glands, teeth, and nails [4]. Growth of dermoid cysts over a period of time can result from

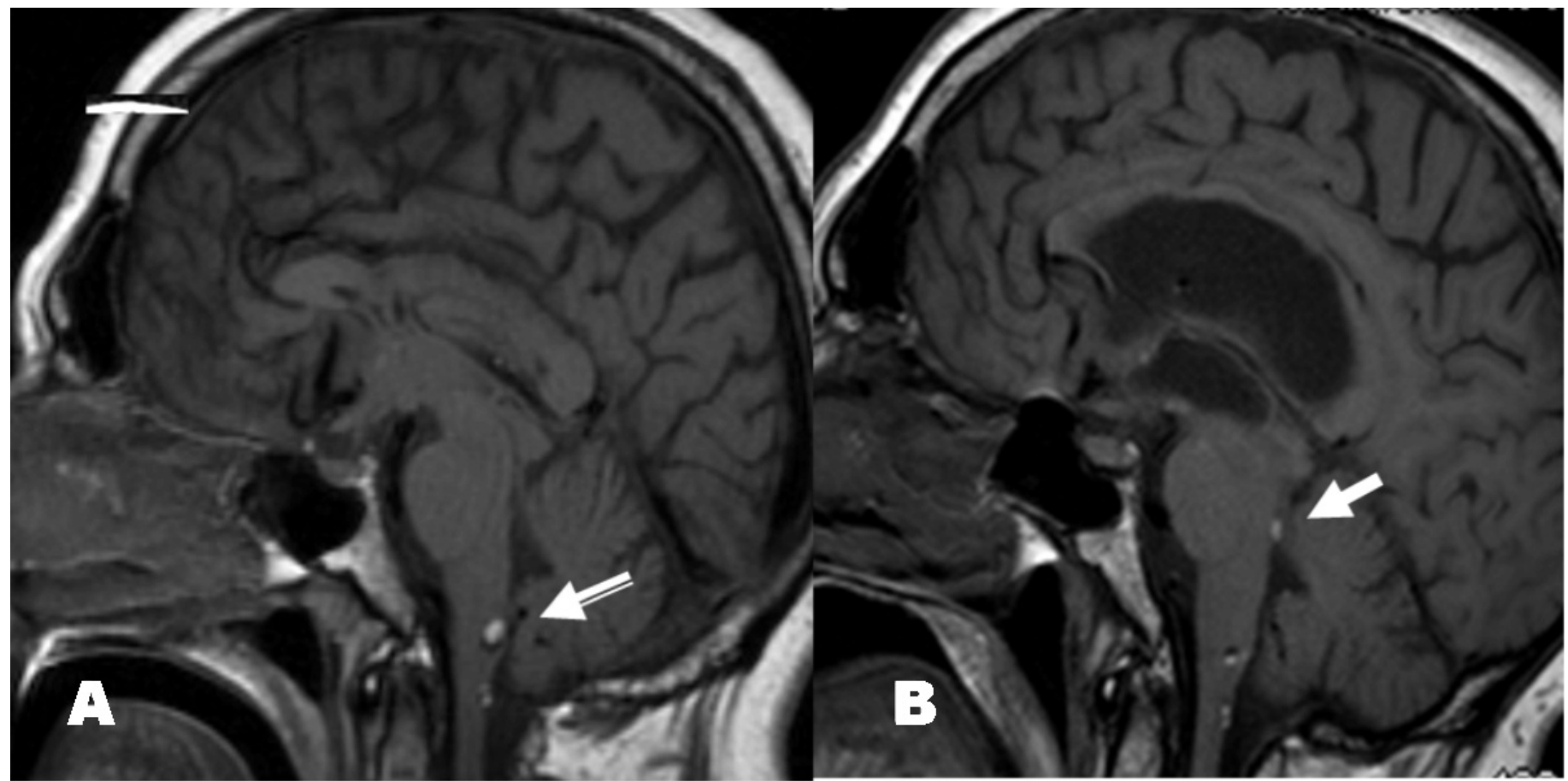

Figure 1: Sagittal T1 MRI brain sequence demonstrating (A) fat droplets within the subarachnoid space dorsal to the medulla (striped arrow), (B) a new fat droplet within the cerebral aqueduct (solid arrow) and obstructive hydrocephalus.

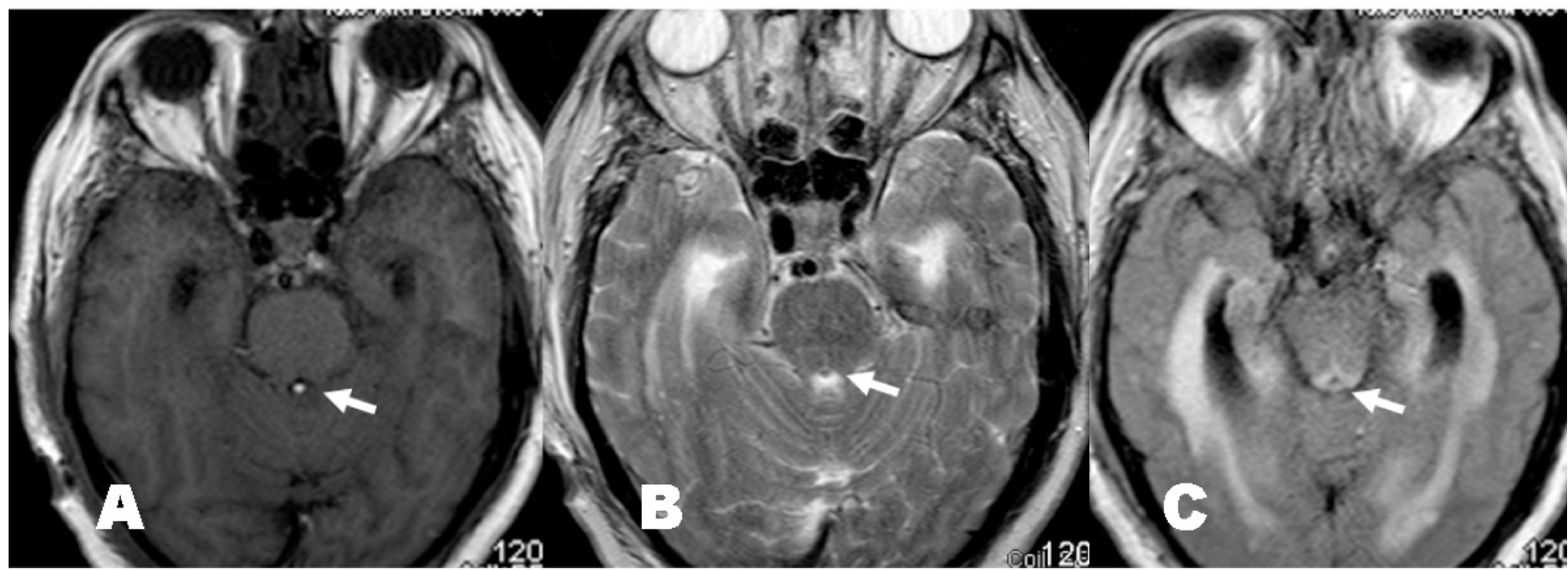

Figure 2: Axial MRI brain sequences with (A) solitary T1 hyperintense, (B) axial T2 hypointense, and (C) axial FLAIR hypointense punctate fat droplet signal within the cerebral aqueduct (white arrows). 
accumulation of cellular debris [1]. The contents of cysts may be vary from patient to patient, which can result in a wide variety of radiographic findings. It is generally accepted, however, that dermoid cysts will appear like fat on computed tomography (CT) and MRI because of their high cholesterol content, yielding hypointensity on CT scan, T1-WI hyperintensity and T2-WI hypointensity on MRI scans [1]. Spinal dermoid cysts can be intramedullary intradural extramedullary or extradural [5]. The majority of intraspinal dermoid tumors occur in the lumbosacral region and rarely in the upper thoracic and cervical regions [5].

The clinical presentation of dermoid cysts in the CNS can vary depending upon the location of the lesion. Neurological symptoms can be a result of compression of surrounding anatomical structures [3]. Patients have also been reported to present with obstructive hydrocephalus as a result of fat in the subarachnoid space from a ruptured dermoid cyst. Usually patients presenting with obstructive hydrocephalus have intracranial tumors. There are only two reported cases of hydrocephalus resulting from intraspinal dermoid tumor rupture [2]. In both these cases, hydrocephalus occurred before resection of the dermoid tumor. The patient in our case had a spinal dermoid tumor resection with a subsequent fifty one year delay before developing acute non-communicating hydrocephalus at the cerebral aqueduct.

There are few long term post-operative studies of patients with resected dermoid tumors. One study of a patient with an intracranial dysontogenic cyst removal demonstrated fat in the subarachnoid space after surgical removal of an intracranial tumor. The annual follow-up imaging did not demonstrate migration of the fat. Additionally, there were no complications as a result of the fat [3]. Recurrence of intracranial dermoids after resection has been documented in literature $[6,7]$.

In our case the patient had resection of a cervical extramedullary, intradural dermoid cyst. Magnetic resonance imaging in 2007 showed fat in the subarachnoid space of the posterior fossa and a patent cerebral aqueduct. The patient then developed acute onset non-communicating hydrocephalus in 2010 as result of a solitary fat droplet obstruction at the cerebral aqueduct. Delayed onset of non-communicating hydrocephalus (after five decades), in the setting of a post-spinal dermoid resection, has not been previously reported in literature.

\section{CONCLUSION}

This study illustrates the importance of ongoing imaging and clinical follow-up of surgically treated spinal dermoid cysts. In particular, increased surveillance for non-communicating hydrocephalus should be practised because spinal dermoid tumors can cause intracranial pathology through retrograde flow of fat droplets.

\section{Author Contributions}

Hetal Patel - Acquisition of data, Analysis and interpretation of data, Drafting the article, Final approval of the version to be published

Michael A Casey - Analysis and interpretation of data, Final approval of the version to be published

Ajeet Gordhan - Conception and design, Analysis and interpretation of data, Critical revision of the article, Final approval of the version to be published

\section{Guarantor}

The corresponding author is the guarantor of submission.

\section{Conflict of Interest}

Authors declare no conflict of interest.

\section{Copyright}

(C) Hetal Patel et al. 2013; This article is distributed under the terms of Creative Commons Attribution 3.0 License which permits unrestricted use, distribution and reproduction in any means provided the original authors and original publisher are properly credited. (Please see www.ijcasereportsandimages.com /copyright-policy.php for more information.)

\section{REFERENCES}

1. Orakcioglu B, Halatsch ME, Fortunati M, Unterberg A, Yonekawa Y. Intracranial dermoid cysts: variations of radiological and clinical features. Acta Neurochir (Wien) 2008 Dec;150(12):1227-34.

2. Cavazzani P, Ruelle A, Michelozzi G, Andrioli G. Spinal dermoid cysts originating intracranial fat drops causing obstructive hydrocephalus: case reports. Surg Neurol 1995 May;43(5):466-9.

3. Carvalho GA, Cervio A, Matthies C, Samii M. Subarachnoid fat dissemination after resection of a cerebellopontine angle dysontogenic cyst: case report and review of the literature. Neurosurgery 2000 Sep;47(3):760-3.

4. Cha JG, Paik SH, Park JS, Park SJ, Kim DH, Lee HK. Ruptured spinal dermoid cyst with disseminated intracranial fat droplets. $\mathrm{Br} \mathrm{J}$ Radiol 2006 Feb;79(938):167-9.

5. Altay H, Kitis O, Calli C, Yünten N. A spinal dermoid tumor that ruptured into the subarachnoidal space and syrinx cavity. Diagn Interv Radiol 2006 Dec;12(4):171-3.

6. Park SK, Cho KG. Recurrent intracranial dermoid cyst after subtotal removal of traumatic rupture. Clin Neurol Neurosurg 2012 May;114(4):421-4.

7. Liu JK, Gottfried ON, Salzman KL, Schmidt RH, Couldwell WT. Ruptured intracranial dermoid cysts: clinical, radiographic, and surgical features. Neurosurgery 2008 Feb;62(2):377-84. 
Access PDF of article on other devices other devices

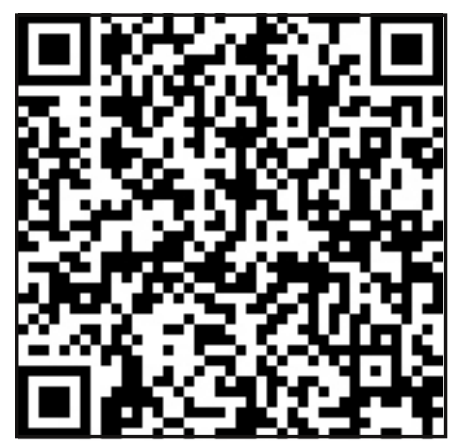

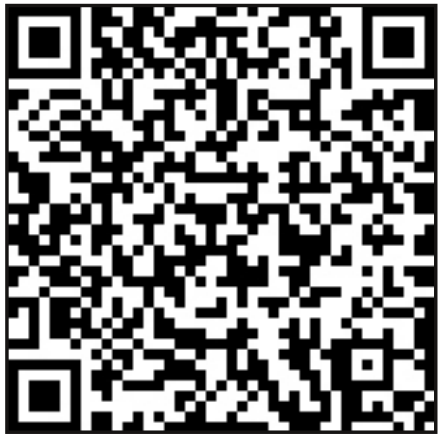

